\title{
The effect of capsaicin and diethylnitrosamine on mouse nephrotoxicity, hepatotoxicity and hepatocarcinogenesis
}

\author{
Vendula Kuchařová Kumžáková ${ }^{1}$, Ivana Veselá ${ }^{1}$, Miša Škorič², Ondřej Daněk ${ }^{1}$,

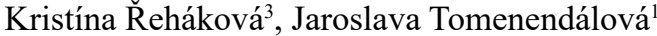 \\ University of Veterinary and Pharmaceutical Sciences Brno, Faculty of Veterinary Medicine, \\ ${ }^{1}$ Department of Physiology, ${ }^{2}$ Department of Pathological Morphology and Parasitology, \\ ${ }^{3}$ Clinic Laboratory for Small Animals, Faculty of Veterinary Medicine, Brno, Czech Republic
}

Received January 16, 2020

Accepted December 21, 2020

\begin{abstract}
Diethylnitrosamine is well known for its toxic and carcinogenic properties affecting mainly liver and kidneys. Capsaicin has been proven in previous years as a promising protective agent against many health problems affecting modern people. In this study we used diethylnitrosamine induced mouse experimental model of liver and kidney damage to assess the potential chemopreventive effect of capsaicin in vivo. Fifty female ICR mice were randomly divided into five groups intraperitoneally administered $1 \%$ ethanol solution in controls, capsaicin to assess its toxicity, diethylnitrosamine alone, and diethylnitrosamine and capsaicin in combination in different manners in two groups. After 14 weeks all mice were sacrificed, complete necropsy was performed and liver and kidneys were used for further examination. Slides of both organs stained with haematoxylin and eosin were histologically evaluated and immunohistochemical detection of proliferating cell nuclear antigen and glutamine synthetase in the liver tissue was performed. Histological evaluation of the liver and kidneys revealed toxic damage of diethylnitrosamine treated animals, whereas mice that received the combination of the substances showed milder lesions. Proliferating cell nuclear antigen expression was lower in diethylnitrosamine treated animals compared to the control and capsaicin groups, pointing to a disruption of the proliferative activity of hepatocytes in the juvenile liver. Glutamine synthetase expression did not differ between the groups, indicating that no tumours were induced by any of the substances used in our study. In conclusion, our experiment demonstrated the toxic properties of diethylnitrosamine in mice liver and kidneys, with the promising beneficial effect of capsaicin.
\end{abstract}

Glutamine synthetase, liver, kidney, proliferating cell nuclear antigen

Cancer is one of the leading causes of morbidity and mortality worldwide. In 2012, approximately 14 million new cases have emerged globally and in 2015 cancer accounted for 8.8 million of deaths (Stewart and Wild 2014; WHO 2018). In 2017, about 1688780 new cancer diagnoses and 600920 cancer deaths were estimated in the United States and the predicted number of cancer deaths in the European Union for 2017 was 1373500 (Malvezzi et al. 2017; Siegel et al. 2017). Liver cancer is the second most common cause of cancer death after lung cancer and the most common primary malignancy of the liver is the hepatocellular carcinoma (HCC) (Stuver and Trichopoulos 2008; WHO 2018). The aetiology and pathogenesis of HCC is very heterogeneous but there is a significant role of both intrinsic genetic factors and extrinsic influences such as viral infections (hepatitis $\mathrm{B}$ and $\mathrm{C}$ ), alcohol or other chronic liver disease that predispose one to the HCC development (Ghouri et al. 2017). Almost 90\% of HCC in humans arises from cirrhosis and there is a clear association between HCC and chronic inflammation or fibrosis (Seitz and Stickel 2006; Zhang and Friedman 2012).

Nitrosamines are substances well known for their toxic properties, the effect of dimethylnitrosamnie (DMN) on liver damage was reported as early as in 1937 (Freund 1937). Currently, one of the most commonly used experimental models for liver damage 
and carcinogenesis is the application of diethylnitrosamine (DEN). Many experimental protocols were designed with different application routes, duration of treatment or combination with other promoting agents. It was also found that many factors such as animal species, specific strain, age or sex can influence the process of carcinogenesis. An attractive model for hepatotoxicity and hepatocarcinogenesis represents a single intraperitoneal (IP) injection to infant mice at a high dose or in combination with subsequent application with a promoting agent like phenobarbital, alcohol or carbon tetrachloride (Heindryckx et al. 2009; Tolba et al. 2015). In addition to liver damage, nephrotoxicity of DEN has been proven in rats (Rezaie et al. 2013; Pashmforoosh et al. 2015).

Capsaicin (trans-8-methyl-N-vanillyl-6-nonenamide) (CAP), a molecule found in the fruit of the Capsicum plant family, is an alkaloid responsible for their typical spicy feature. Its biological effect has been studied for more than a century with promising results mainly in regard to pain relief, inflammation, obesity and even cancer treatment or cancer prevention (Sharma et al. 2013). On the contrary, some authors described the genotoxic and carcinogenic potential, mainly in older studies where plant extracts containing also other capsaicinoids and diverse impurities were used. Nowadays pure capsaicin is understood widely as a dietary chemopreventive agent (Bley et al. 2012; Díaz-Laviada and Rodríguez-Henche 2014). In our previous study we demonstrated the toxicity of low-dose CAP on tumour fibroblasts with high-dose CAP exerting toxic properties also in normal mouse fibroblasts, liver- and kidney-derived cells from fallow deer (Veselá et al. 2018).

In this study we used a DEN-induced mouse experimental model of liver and kidney damage to assess the potential chemopreventive effect of CAP in vivo and we also aimed to verify the non-toxicity of CAP in a commonly used dose in mouse liver and kidney.

\section{Materials and Methods}

Chemicals

Diethylnitrosamine (DEN, Sigma-Aldrich, Missouri, USA) was dissolved in saline $(0.9 \% \mathrm{NaCl})$. Capsaicin (CAP, Merck Millipore, Missouri, USA) was first dissolved in ethanol to a stock solution and this was further dissolved in saline to form a final solution containing 0.1 or $0.05 \mathrm{mg}$ CAP in $1 \mathrm{ml} 1 \%$ ethanol solution (dosage $1.5 \mathrm{mg} / \mathrm{kg}$ body weight [BW] or $0.75 \mathrm{mg} / \mathrm{kg} \mathrm{BW}$ ). The doses of capsaicin were set up according a previous study (Díaz Barriga et al. 1995).

Animals and experimental conditions

Female ICR mice (13-16 g, 3-4 weeks old) were obtained from AnLab s.r.o. (Prague, Czech Republic). After two weeks of quarantine and acclimatization, mice were randomly divided into five groups (10 mice per group), housed in plastic cages ( 5 mice per cage) with sawdust as bedding and 12-h light/dark cycle; temperature and humidity were monitored twice a day. Drinking water and standard mouse diet (Biokron s.r.o., Blučina, Czech Republic) were provided ad libitum throughout the experiment.

All animal experimental procedures were conducted according to the Czech animal welfare protection legal guidelines and the EU Directive. Paper rolls were used to provide environmental enrichment.

Experimental design

A total of 50 female ICR mice were randomly divided into five groups. Mice from the first group (control, CON, $n=10)$ were administered ethanol solution (1\%) IP in weeks 3, 5, 7, 9, 11 and 14. Mice in the second group (CAP, $\mathrm{n}=10)$ were administered CAP IP at a dose of $1.5 \mathrm{mg} / \mathrm{kg} \mathrm{BW}$ in weeks 3 and 5 and due to impaired tolerance, the dose was halved in weeks $7,9,11$ and $14(0.75 \mathrm{mg} / \mathrm{kg} \mathrm{BW})$. The third group $(\mathrm{DEN}, \mathrm{n}=10)$ was administered DEN IP at a dose of $25 \mathrm{mg} / \mathrm{kg} \mathrm{BW}$ (about 1/5 LD50) at week 2. Mice in the fourth group (CAP-DEN, $\mathrm{n}=10$ ) were administered CAP IP at a dose of $1.5 \mathrm{mg} / \mathrm{kg} \mathrm{BW}$ in week 1 and a week after DEN IP at a dose of $25 \mathrm{mg} / \mathrm{kg} \mathrm{BW}$. In week 14, half of the group were administered DEN IP at the same dose and the rest received only saline. Mice in the last group (DEN-CAP, $n=10$ ) were administered DEN IP at a dose of $25 \mathrm{mg} / \mathrm{kg}$ $\mathrm{BW}$ in week 2 and from week $3 \mathrm{CAP}$ as the second group (CAP). Due to impaired tolerance, the dose of CAP was also decreased from week 7. Half of the last group was administered another dose of DEN $(25 \mathrm{mg} / \mathrm{kg} \mathrm{BW})$ a day after the last CAP injection. Twenty-four hours after the last application, all mice were euthanized using ether overdose and decapitation. The experimental design is depicted in Table 1. 
Table 1. Experimental design.

\begin{tabular}{|c|c|c|c|c|c|c|c|c|c|c|c|}
\hline Group & Accl. & W1 & W2 & W3 & W5 & W7 & W9 & W11 & W14 & +1 day & +1 day \\
\hline $\mathrm{CON}$ & & & & ETOH & ETOH & ETOH & ETOH & ETOH & ETOH & EUT & \\
\hline CAP & & & & CAP & CAP & CAP & CAP & CAP & CAP & EUT & \\
\hline \multirow[t]{2}{*}{ DEN } & & & DEN & & & & & & & EUT & \\
\hline & & & & & & & & & $1 / 2 \mathrm{DEN}$ & & \\
\hline \multirow[t]{3}{*}{ CAP-DEN } & & CAP & DEN & & & & & & & EUT & \\
\hline & & & & & & & & & $1 / 2 \mathrm{~S}$ & & \\
\hline & & & & & & & & & & $1 / 2$ DEN & \\
\hline DEN-CAP & & & DEN & CAP & CAP & CAP & CAP & CAP & CAP & $1 / 2 \mathrm{~S}$ & EUT \\
\hline
\end{tabular}

Accl. = acclimatization, $\mathrm{W}=$ week, ETOH $=1 \%$ ethanol, EUT $=$ euthanasia, $\mathrm{CAP}=$ capsaicin, $\mathrm{DEN}=$ diethylnitrosamine, $\mathrm{S}=$ saline

The animals were observed daily throughout the experiment to assess their general health and their BW was measured weekly.

Sample collection

After sacrifice, complete necropsy was performed and liver and kidneys were examined macroscopically, fixed in $10 \%$ buffered formalin and the representative parts were embedded in paraffin wax.

\section{Histological evaluation}

Tissue sections of $4 \mu \mathrm{m}$ were processed and routinely stained with haematoxylin and eosin (H\&E). Slides were observed under light microscopy (magnification $\times 200$ and $\times 400$ ) by an experienced histopathologist in a blind fashion.

Immunohistochemical procedures

Two liver sections of $1 \mu \mathrm{m}$ from each mouse were used for immunohistochemical staining. To detect replicating cells, an endogenous marker of cell proliferation (proliferating cell nuclear antigen, PCNA) was used and as an early marker for hepatocellular carcinoma glutamine synthetase (GS) was used. Primary antibodies were obtained from Santa Cruz (PCNA Antibody (PC10): sc-56; Santa Cruz Biotechnology, Dallas, TX, USA) and Abcam (Anti-Glutamine Synthetase antibody, ab49873; Abcam, Cambridge, MA, USA). Secondary antibodies and ABC complex were a part of VECTASTAIN ABC HRP Kit (PK-4001 and PK-4002; Vector Laboratories, Burlingame, CA, USA) and diaminobenzidine (DAB) was provided by Dako (K3468; Dako, Carpinteria, CA, USA). All the procedures were carried out according to the manufacturer's instructions. Briefly, sections were deparaffinised in 2 changes of xylene for $10 \mathrm{~min}$ and rehydrated in alcohol solutions with decreasing concentrations. Antigen retrieval was performed using $10 \mathrm{mmol} / \mathrm{l}$ sodium citrate buffer $(\mathrm{pH} 6.0)$ in a microwave oven. Endogenous peroxidase was inactivated in 3\% hydrogen peroxide solution for $10 \mathrm{~min}$. After $20 \mathrm{~min}$, incubation with protein block serum, primary antibody was applied to the slide for $2 \mathrm{~h}$ at room temperature in a humidified chamber. Then, after $30 \mathrm{~min}$ of incubation with secondary antibody, the ABC complex was used for further $30 \mathrm{~min}$. The reaction was visualised with $\mathrm{DAB}$ and haematoxylin was used for counterstaining.

\section{Scoring}

Sections were semi-quantitatively evaluated and scored according to the number of immunoreactive (IR) cells. Positive signal for GS was in the cytoplasm and for the PCNA in the nucleus. For PCNA we counted IR cells in a 2-high-power field ( $\times 400$ magnification) and expressed the result as a percentage of IR cells. We also evaluated the staining intensity (SI) on the scale of 0-3 (0 - absent, 1 - weak, 2 - moderate, 3 - strong). For GS, we evaluated the SI and the localization of IR cells as perivenular, periportal or diffuse.

\section{Results}

During the experiment, 3 mice died after CAP administration; 2 in week 3 and 1 in week 5. The death occurred a few minutes after CAP application and signs of peritonitis and shock were found during necropsy. In some mice we observed impaired tolerance to CAP approximately $15 \mathrm{~min}$ after IP injection, increased breathing and reduced mobility. After a dose reduction from week 7 , none of the mice showed any negative response to CAP. 
Besides this, we did not find any external clinical signs of disease in any of the mice during the experiment.

Food and water intake as well as BW did not differ between the groups during the experimental period and at the end of the experiment (data not shown).

\section{Macroscopic evaluation}

During necropsy, no macroscopic changes were seen in the kidneys. In only DENexposed mice the structure of the liver was fragile compared to other groups and in some mice, small pale hepatic nodules measuring between 1 and $2 \mathrm{~mm}$ in diameter were observed (Plate XY, Fig. 1a). In 1 mouse an ovarian cyst of approximately $2 \mathrm{~cm}$ in diameter was found which was probably unrelated to the experimental procedures. In the control group, macroscopic evaluation revealed normal liver and kidney architecture (Plate IV, Fig. 1b).

\section{Histological evaluation}

In control groups, both liver and kidneys revealed undamaged histological structure. In DEN-exposed mice multifocal inflammatory lesions formed by mononuclear cells were found both in the liver and kidneys. Localization of deposits in the liver was mainly around the central vein but some were disseminated across the parenchyma. In the kidneys, mononuclear cells were found in the cortex around glomeruli and in the medulla around tubules. In both groups where CAP was used before or after DEN administration, the number and extent of inflammatory cell infiltration were reduced. These inflammatory lesions were rarely found in small extent in some CAP-treated mice, as well. In addition, the liver of DEN-exposed mice revealed other toxic changes like hydropic degeneration, anisokaryosis, pyknotic nuclei or cytoplasmic eosinophilia. In the kidneys in group DEN necrosis, glomerular atrophy, increased Bowman's space, perivascular oedema and granular dystrophy of epithelial tubular cells were observed. On the other hand, in 1 mouse from group CAP, some mitotic figures were found in the liver parenchyma. The most important histological findings are summarized in Figs 2 and 3 (Plates IV, V).

\section{Immunohistochemical analysis}

Mean percentage of immunoreactive cells and staining intensity for PCNA detection in mice of different groups is shown in Table 2. A representative picture of liver stained

Table 2. Proliferating cell nuclear antigen (PCNA) immunoreactivity of hepatocytes in different groups.

\begin{tabular}{lcc} 
Group & IR cells [\%] & SI $(0-3)$ \\
\hline CON & 3.9 & $2-3$ \\
CAP & 3.9 & 2 \\
DEN & 0.7 & 1 \\
CAP-DEN & 2.2 & 1 \\
DEN-CAP & 1.9 & $1-2$ \\
\hline
\end{tabular}

IR - immunoreactive, SI - staining intensity, CON - control, CAP - capsaicin, DEN diethylnitrosamine with PCNA antibody in a CAP-treated mouse is shown in Fig. 4a (Plate V).

GS expression was mainly perivenular in $\mathrm{CON}$ and CAP groups with weak to moderate SI (Plate V, Fig. 4b). Only rarely we observed immunoreactive cells diffuse in the parenchyma in group DEN which was proven also in groups receiving a combination of DEN and CAP both before and after DEN application (Plate V, Fig. 4c). The SI did not differ significantly between groups and different deposits of IR cells and was mostly weak to moderate.

\section{Discussion}

Diethylnitrosamine is reported as a well-known toxic agent and potent hepatocarcinogen and is used as an experimental model of liver injury in rodents. However, many factors including animal species and strain, age, and sex, application route, dosage or duration of treatment can influence the development of organ lesions (Kushida et al. 2011; Santos 
et al. 2014; Tolba et al. 2015). In our study we chose a single IP injection of DEN $(25 \mathrm{mg} / \mathrm{kg} \mathrm{BW})$ to young mice without any promotion which was proven to induce liver cancer earlier (Schneider et al. 2012; Wang et al. 2018). However, the duration of our experiment was not sufficient to show neoplastic lesions in the liver or kidneys; at least toxic changes have been demonstrated.

Visible macroscopic lesions in mice were described 15 weeks after the first DEN application in the form of a whitish-coloured lesion with a diameter of less than $1 \mathrm{~mm}$ (Santos et al. 2012). In other studies, macroscopic hepatic changes were observed up to 22 weeks after the start of experiment and their number and size were increasing with the duration of the experiment (Da Costa et al. 2014; Santos et al. 2014). In our study, some small hepatic nodules were rarely found in DEN-treated mice which is consistent with previously reported data. Likewise, no macroscopic changes were described in the kidneys of DEN-treated mice in our study as well as in other studies (Rezaie et al. 2013).

Histological changes caused by toxic and carcinogenic substances such as DEN can be divided into 2 basic groups: toxic lesions and proliferative lesions. The latter are typical for prolonged experiments, whereas toxic changes can reflect also acute and short-term exposure as described previously (Da Costa et al. 2014; Santos et al. 2014; Tolba et al. 2015). All the hepatic lesions observed in our study can be categorized as toxic; proliferative lesions were not found in any DEN-treated animal. Da Costa et al. (2014) described toxic hepatic changes in mice as early as $18 \mathrm{~h}$ after the last administration of DEN, whereas the first proliferative lesions were observed 29 weeks after the first administration (21 weeks after the last administration). Hepatocellular carcinoma was found only in mice euthanized 40 weeks after the start of the experiment (Da Costa et al. 2014). In the kidneys of DENtreated rats, Rezaie et al. (2013) found mainly necrotic lesions in the renal tubules, which is in agreement with our result. In mice treated with multiple carcinogens including DEN, renal tubular degeneration, tubular cell hyperplasia and in one case also renal adenoma were described. However, in this study it is questionable whether these lesions were caused by DEN or another carcinogen used (Kakehashi et al. 2017). Other studies evaluating the effect of DEN and CAP on renal histology in mice have not been published; our results therefore provide a new insight into the possible effects of these substances.

Combination of DEN and CAP was tested in rats in previous years with different results. Jang and Kim (1988) tested the influence of CAP on the development of DENinitiated hepatic lesions in rats with a pronounced promoting effect of CAP. In other studies, formation of these preneoplastic hepatic lesions was both significantly inhibited in a multiorgan carcinogenesis model (Jang et al. 1991) and not affected by CAP administration (Toyoda-Hokaiwado et al. 2011). In the latter study, the authors found only slightly reduced incidence and multiplicity of liver tumours in rats receiving a combination of DEN and CAP in comparison with only DEN-treated animals (Toyoda-Hokaiwado et al. 2011). Mohammed et al. (2014) also described the chemopreventive and therapeutic effect of CAP in DEN-induced liver injury in rats when the hepatic histological features were improved in animals receiving CAP both as a preventive and a therapeutic agent. In any of the above-mentioned studies, CAP alone did not cause any change indicating its possible toxic or carcinogenic potential. In our study, we lean towards the protective effect of CAP on DEN-induced organ damage, however, the effect of CAP alone is questionable due to the presence of a few small inflammatory cell infiltrations in both examined organs and mitotic figures in the liver of some animals.

The PCNA is a highly conserved protein that plays a crucial role in DNA replication, DNA repair, the cell cycle and apoptosis and is widely used as a marker of cell proliferation, which was proven in rodent hepatocytes as well (Eldrige et al. 1993; Park et al. 2016). Since tumours have a generally high proliferative activity, PCNA serves as a diagnostic and prognostic marker in many types of cancer (Park et al. 2016). Normal liver tissue showed 
in few cases only weak PCNA immunoreactivity whereas the number and intensity was increasing in cirrhotic liver and mostly in HCC (Ojanguren et al. 1993; Mun et al. 2006). When PCNA expression was investigated in the liver of DEN-treated mice, it tended to increase, pointing to enhanced proliferation of hepatocytes (Chuang et al. 2000; Sun et al. 2012; Kang et al. 2013). On the contrary, in our study the proliferation rate was decreased in DEN-treated animals compared to the control group. This finding can be explained by the fact that the duration of our experiment was not sufficient for tumour development and the decreased proliferation rate was rather due to the toxic effect of DEN on the young developing liver of juvenile mice.

Glutamine synthetase in the mammalian liver is a cytosolic enzyme converting ammonia to glutamine and its distribution is predominantly restricted to the zone of hepatocytes surrounding the central vein (Smith and Campbell 1988; Hu et al. 2018). The expression of GS is stronger and diffuse in liver tumours, predominantly in HCC and therefore detection of GS is used as one of the markers of hepatocarcinogenesis (Koehne et al. 2015; Wasfy and Shams Eldeen 2015). As mentioned before, the design of our study was not appropriate for liver tumour development, therefore, the GS expression did not differ between the groups.

In conclusion, our experiment demonstrated the toxic properties of DEN in the liver and kidneys of mice with a promising beneficial effect of CAP. Another study with more detailed analysis is needed to confirm this hypothesis and bring more information on the mechanisms of action. Due to some small organ lesions in CAP-treated animals, we cannot confirm the nontoxicity of CAP, therefore, we recommend another experiment with different doses of CAP to verify our hypothesis. To evaluate the potential chemopreventive effect of CAP on hepatocarcinogenesis and to provide a better insight into its mechanism of action, another experimental design would be necessary.

\section{Acknowledgement}

This work was supported by the Internal Grant Agency of the University of Veterinary and Pharmaceutical Sciences Brno, Grant No. 114/2016/FVL.

\section{References}

Bley K, Boorman G, Mohammad B, McKenzie D, Babbar S 2012: A comprehensive review of the carcinogenic and anticarcinogenic potential of capsaicin. Toxicol Pathol 40: 847-873

Chuang SE, Kuo ML, Hsu CH, Chen CR, Lin JK, Lai GM, Hsieh CY, Cheng AL 2000: Curcumin-containing diet inhibits diethylnitrosamine-induced murine hepatocarcinogenesis. Carcinogenesis 21: 331-335

Da Costa RM, Santos NP, Rocha AF, Colaço A, Lopes C, Oliveira PA 2014: The N-nitrosodiethylamine mouse model: sketching a timeline of evolution of chemically-induced hepatic lesions. Anticancer Res 34: 7029-7037

Díaz Barriga Arceo S, Madrigal-Bujaidar E, Calderón Montellano E, Ramírez Herrera L, Díaz García BD 1995: Genotoxic effects produced by capsaicin in mouse during subchronic treatment. Mutat Res 345: 3-4

Díaz-Laviada I, Rodríguez-Henche N 2014: The potential antitumor effects of capsaicin. Prog Drug Res 68: 181-208

Eldrige SR, Butterworth BE, Goldsworthy TL 1993: Proliferating cell nuclear antigen: a marker for hepatocellular proliferation in rodents. Environ Health Perspect 101: 211-218

Freund HA 1937: Clinical manifestation and studies in parenchymatous hepatitis. Ann Intern Med 10: 1144-1155

Ghouri YA, Mian I, Rowe JH 2017: Review of hepatocellular carcinoma: Epidemiology, etiology, and carcinogenesis. J Carcinog 16: 1

Heindryckx F, Colle I, Van Vlierberghe H 2009: Experimental mouse models for hepatocellular carcinoma research. Int J Exp Pathol 90: 367-386

Hu QX, Ottestad-Hansen S, Holmseth S, Hassel B, Danbolt NC, Zhou Y 2018: Expression of glutamate transporters in mouse liver, kidney, and intestine. J Histochem Cytochem 66: 189-202

Jang JJ, Kim SH 1988: The promoting effect of capsaicin on the development of diethylnicrosamine-initiated enzyme altered hepatic foci in male Sprague Dawley rats. J Korean Cancer Assoc 20: 1-8

Jang JJ, Cho KJ, Lee YS, Bae JH 1991: Different modifying responses of capsaicin in a wide-spectrum initiation model of F344 rat. J Korean Med Sci 6: 31-36

Kakehashi A, Ishii N, Okuno T, Fujioka M, Gi M, Wanibuchi H 2017: Enhanced susceptibility of Ogg1 mutant mice to multiorgan carcinogenesis. Int J Mol Sci 18: 1801 
Kang JS, Kang HG, Park YI, Lee H, Park K, Lee YS, Kim S, Ryu DY 2013: Expression of epithelial cell adhesion molecule and proliferating cell nuclear antigen in diethylnitrosamine-induced hepatocarcinogenesis in mice. Exp Ther Med 5: 138-142

Koehne de Gonzalez AK, Salomao MA, Lagana SM 2015: Current concepts in the immunohistochemical evaluation of liver tumors. World J Hepatol 7: 1403-1411

Kushida M, Kamendulis LM, Peat TJ, Klaunig JE 2011: Dose-related induction of hepatic preneoplastic lesions by diethylnitrosamine in C57BL/6 mice. Toxicol Pathol 39: 776-786

Malvezzi M, Carioli G, Bertuccio P, Boffetta P, Levi F, La Vecchia C, Negri E 2017: European cancer mortality predictions for the year 2017, with focus on lung cancer. Ann Oncol 28: 1117-1123

Mohammed FZ, Sultan AS, Abas AM 2014: Chemopreventive and therapeutic effect of capsaicin against diethylnitrosamine induced liver injury and hepatocellular carcinoma in rats. Int J Biol Pharm Res 5: 630-642

Mun KS, Cheah PL, Baharudin NB, Looi LM 2006: Proliferating cell nuclear antigen (PCNA) activity in hepatocellular carcinoma, benign peri-neoplastic and normal liver. Malays J Pathol 28: 73-77

Ojanguren I, Ariza A, Llatjós M, Castellà E, Mate JL, Navas-Palacios JJ 1993: Proliferating cell nuclear antigen expression in normal, regenerative, and neoplastic liver: a fine-needle aspiration cytology and biopsy study. Hum Pathol 24: 905-908

Park SY, Jeong MS, Han CW, Yu HS, Jang SB 2016: Structural and functional insight into proliferating cell nuclear antigen. J Microbiol Biotechnol 26: 637-647

Pashmforoosh M, Rezaie A, Haghi-Karamallah M, Fazlara A, Shahriari A, Najafzadeh H 2015: Effects of caffeine on renal toxicity induced by diethylnitrosamine. Zahedan J Res Med Sci 17: 7-9

Rezaie A, Fazlara A, Haghi Karamolah M, Shahriari A, Najaf Zadeh H, Pashmforosh M 2013: Effects of Echinacea purpurea on hepatic and renal toxicity induced by diethylnitrosamine in rats. Jundishapur $\mathrm{J}$ Nat Pharm Prod 8: 60-64

Santos NP, Pereira IC, Pires MJ, Lopes C, Andrade R, Oliveira MM, Colaço A, Peixoto F, Oliveira PA 2012: Histology, bioenergetics and oxidative stress in mouse liver exposed to N-diethylnitrosamine. In Vivo 26: 921-929

Santos NP, Colaço A, Gil da Costa RM, Oliveira MM, Peixoto F, Oliveira PA 2014: N-diethylnitrosamine mouse hepatotoxicity: time-related effects on histology and oxidative stress. Exp Toxicol Pathol 66: 429-436

Schneider C, Teufel A, Yevsa T, Staib F, Hohmeyer A, Walenda G, Zimmermann HW, Vucur M, Huss S, Gassler N, Wasmuth HE, Lira SA, Zender L, Luedde T, Trautwein C, Tacke F 2012: Adaptive immunity suppresses formation and progression of diethylnitrosamine-induced liver cancer. Gut 61: 1733-1743

Seitz HK, Stickel F 2006: Risk factors and mechanisms of hepatocarcinogenesis with special emphasis on alcohol and oxidative stress. Biol Chem 387: 349-360

Sharma SK, Vij AS, Sharma M 2013: Mechanisms and clinical uses of capsaicin. Eur J Pharmacol 720: 55-62

Siegel RL, Miller KD, Jemal A 2017: Cancer statistics, 2017. CA Cancer J Clin 67: 7-30

Smith DD Jr, Campbell JW 1988: Distribution of glutamine synthetase and carbamoyl-phosphate synthetase I in vertebrate liver. Proc Natl Acad Sci USA 85: 160-164

Stewart BW, Wild CP 2014: World cancer report 2014. Lyon, France: International Agency for Research on Cancer

Stuver S, Trichopoulos D 2008: Cancer of the liver and biliary tract. In: Adami HO, Hunter DJ, Trichopoulos D (Eds.): Textbook of Cancer Epidemiology. Oxford University Press, New York, pp. 308-332

Sun H, Yu L, Wei H, Liu G 2012: A novel antihepatitis drug, bicyclol, prevents liver carcinogenesis in diethylnitrosamine-initiated and phenobarbital-promoted mice tumor model. J Biomed Biotechnol 2012: 584728

Tolba R, Kraus T, Liedtke C, Schwarz M, Weiskirchen R 2015: Diethylnitrosamine (DEN)-induced carcinogenic liver injury in mice. Lab Anim 49: 59-69

Toyoda-Hokaiwado N, Yasui Y, Takamune M, Yamada M, Muramatsu M, Masumura K, Ohta T, Tanaka T, Nohmi T 2011: Modulatory effects of capsaicin on N-diethylnitrosamine (DEN)-induced mutagenesis in Salmonella typhimurium YG7108 and DEN-induced hepatocarcinogenesis in gpt delta transgenic rats. Genes and Environment 33: 160-166

Veselá I, Celá Kolísková P, Kuchařová V, Tomenendálová J, Kováčová V, Pikula J, Repková B, Rapekta P, Hrouzek P, Cheel J, Doubek J 2018: Cytotoxic effect of aeruginosin-865, resveratrol and capsaicin on mouse fibroblasts and cells derived from fallow deer. Nat Prod Commun 13: 205-208

Wang B, Fu J, Yu T, Xu A, Qin W, Yang Z, Chen Y, Wang H 2018: Contradictory effects of mitochondria- and non-mitochondria-targeted antioxidants on hepatocarcinogenesis by altering DNA repair in mice. Hepatology 67: $623-635$

Wasfy RE, Shams Eldeen AA 2015: Roles of combined glypican-3 and glutamine synthetase in differential diagnosis of hepatocellular lesions. Asian Pac J Cancer Prev 16: 4769-4775

WHO 2018: Cancer. Available at: www.who.int/mediacentre/factsheets/fs297/en/. Last modified September 12,2018

Zhang DY, Friedman SL 2012: Fibrosis-dependent mechanisms of hepatocarcinogenesis. Hepatology 56: 769-775 
Plate IV

Kuchařová Kumžáková V. et al.: The effect ... pp. 383-389
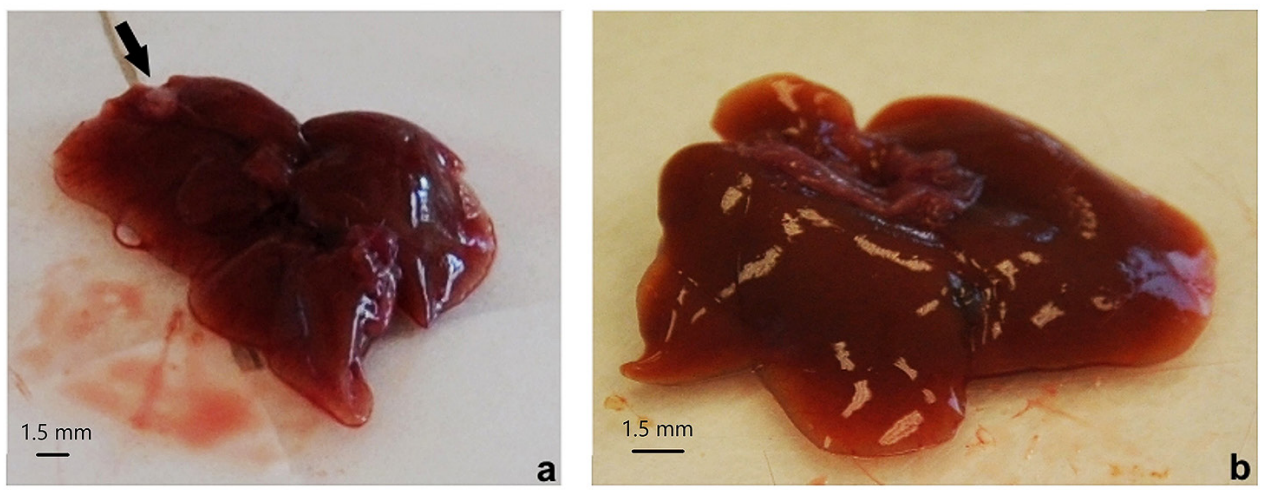

Fig. 1. Macroscopic features of livers: (a) diethylnitrosamine group with single nodule in the parenchyma; (b) control group with preserved architecture
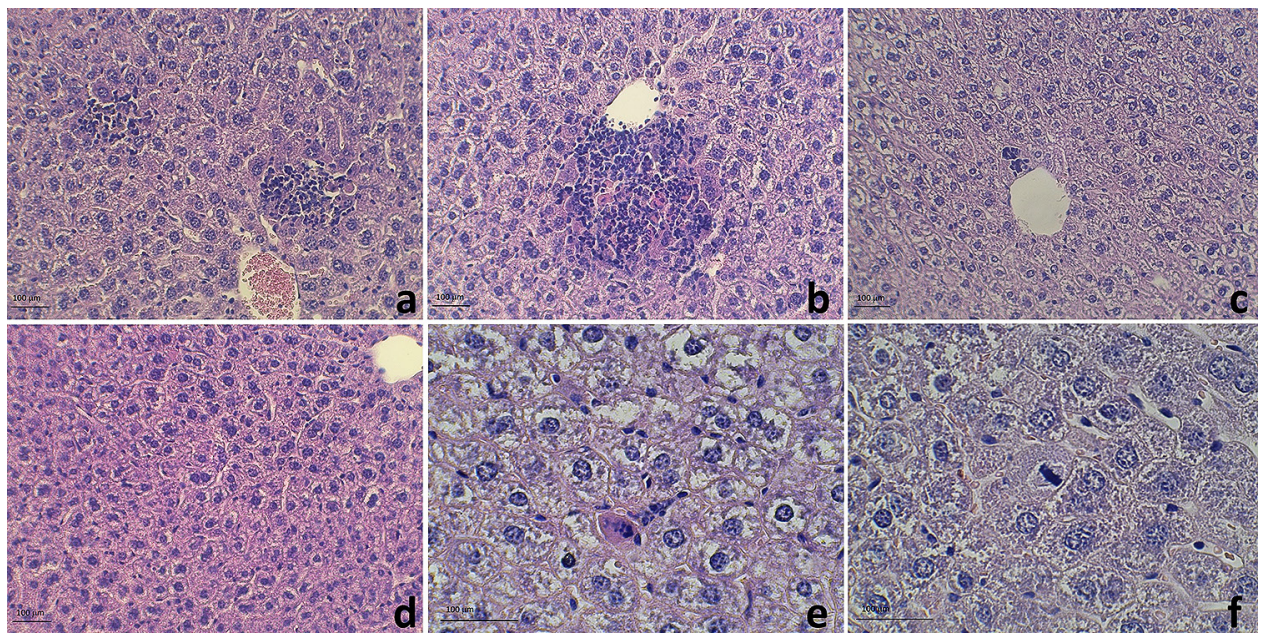

Fig. 2. Hepatic histological lesions of experimental mice stained with haematoxylin and eosin: $(\mathrm{a}, \mathrm{b})$ mononuclear cell infiltration in diethylnitrosamine treated animals, $\times 200$; (c) smaller infiltration in mice from diethylnitrosamine-capsaicin group, $\times 200$; (d) anisokaryosis and cytoplasmic eosinophilia, $\times 200$; (e) hydropic degeneration and necrosis in diethylnitrosamine treated mice, $\times 400$ and (f) mitosis in capsaicin treated mouse, $\times 400$ 

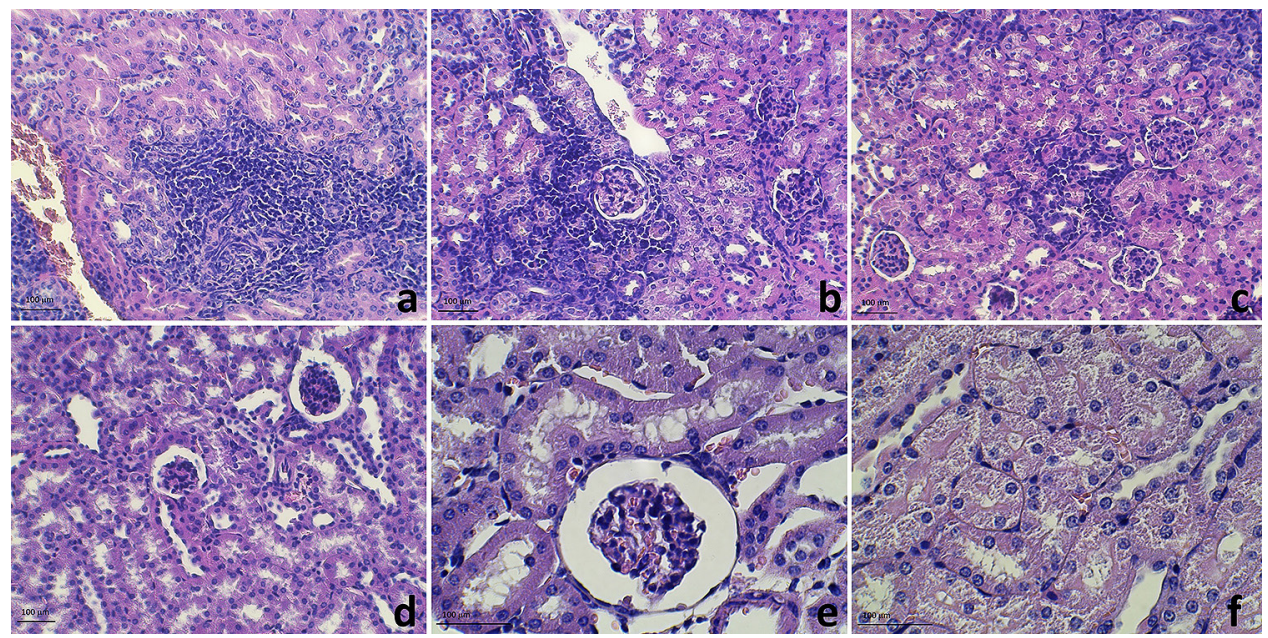

Fig. 3. Renal histological lesions of experimental mice stained with haematoxylin and eosin: (a) mononuclear cell infiltration around renal tubules, $\times 200$ and (b) glomeruli in diethylnitrosamine treated mouse, $\times 200$; (c) smaller infiltration in mice from diethylnitrosamine-capsaicin group, $\times 200$; (d) glomerular atrophy, $\times 200$; (e) increased Bowman's space, $\times 400$ and (f) granular dystrophy of epithelial tubular cells in diethylnitrosamine treated mice, $\times 400$
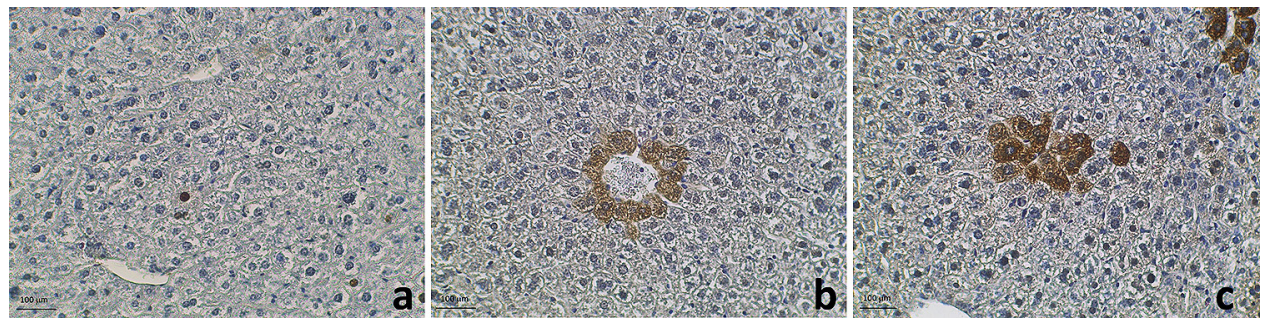

Fig. 4. Immunohistochemical detection of proliferating cell nuclear antigen (PCNA) and glutamine synthetase (GS) in liver sections of control and experimental mice: (a) proliferating cell nuclear antigen expression in a capsaicin treated mouse, $\times 200$; (b) perivenular glutamine synthetase expression in a mouse from the control group, $\times 200$ and (c) a small deposit of glutamine synthetase positive cells in the liver parenchyma in a diethylnitrosamine treated mouse, $\times 200$ 